\title{
Screening acute cytotoxicity biomarkers using a microalga as test organism
}

\author{
Raquel Prado, Carmen Rioboo, Concepción Herrero, Ángeles Cid \\ Laboratorio de Microbiología, Facultad de Ciencias, Universidad de A Coruña. Campus \\ de A Zapateira s/n, 15008A Coruña, Spain
}

\section{Ecotoxicology and Environmental Safety,}

Volume 86, 1 December 2012, Pages 219-226

Received 31 May 2012, Revised 19 September 2012, Accepted 20 September 2012,

Available online 16 October 2012

DOI: 10.1016/j.ecoenv.2012.09.015

\section{Abstract}

The present study checked the suitability of the integration of flow cytometry (FCM) as technique and a freshwater microalga (Chlamydomonas moewusii) as cell system model for ecotoxicological studies, looking for sensitive biomarkers of acute cytotoxicity of potential contaminants in aquatic systems. The detection of the potential acute toxicity of a pollutant is of interest because pulse discharges of contaminants to natural waters could lead to high concentrations of these substances that are only present for short periods of time but can affect aquatic organisms such as microalgae. Physiological alterations in C. moewusiicells were analysed after $1 \mathrm{~h}$ of exposure to different concentrations of the herbicide paraquat. Cell viability was not affected, but the acute toxicity of paraquat was evident at other levels of cell physiology. Herbicidetreated cells showed lower autofluorescence and higher size and internal complexity, lower esterase activity and lower mitochondrial membrane potential. Paraquat induced the depolarisation of the plasma membrane and the increase of intracellular free calcium level and cytosolic $\mathrm{pH}$ in a concentration-dependent percentage of cells. All these effects can be related to the oxidative stress induced by the herbicide, as revealed the significantly increased intracellular levels of reactive oxygen species in cultures exposed to paraquat concentrations which induced the physiological alterations mentioned above. Excluding cell viability and mitochondrial membrane potential, these cytotoxicity endpoints could be considered sensitive biomarkers for the short-term exposure to pollutants such as herbicides. 
Highlights

- This study examine the acute cytotoxicity of paraquat on microalgal physiology.

- Flow cytometric protocols assayed allow the screening of different toxicity cellular endpoints. - Cell viability is not a sensitive biomarker.

- Short-term paraquat exposure induces alteration in the overall cellular ionic homeostasis.

- Most alterations observed could be related with the overproduction of ROS.

\section{Keywords}

Microalga; Flow cytometry; Cytotoxicity; Pollution; Biomarker

\section{Introduction}

Agricultural areas are generally pesticide-dependent and generate water pollution due to transfer of pesticide residues. Their ecological effects in aquatic ecosystems are broad-ranging owing to the variety of substances present (DeLorenzo et al., 2001). In particular, herbicides are widely used to protect crops against adventicious plants, but an excess of them can generate negative effects on the environment. Aquatic nontarget organisms are of primary interest when addressing the potential adverse effects of these pollutants, microalgae an example of them. They are known comparatively sensitive to chemicals (Real et al., 2003) and, because of their short life cycle, often provide one of the first signals of ecosystem impacts. Their primary production and their essential roles in nitrogen and phosphorus cycling are critical to aquatic ecosystems (Källqvist and Svenson, 2003 and Sabater and Carrasco, 2001). Moreover, the alteration of species composition in aquatic community may affect the structure and function of the whole aquatic ecosystem (Rioboo et al., 2007).

The authorisation for pesticide commercialisation in Europe currently requires previous testing of potential negative effects of the active ingredients on non-target aquatic organisms (Pereira et al., 2009). It is necessary the development of methods for the detection of contaminants based on the physiological response of organisms to provide an early warning of sublethal pollution. It is also desirable being able to test the acute toxicity of chemicals on response variables that are sensitive to sublethal 
concentrations. Algal growth bioassays remain the preferred technique for assessment of phytotoxic effects in most ecotoxicological studies (Tai et al., 2010) since growth is a population parameter that tends to integrate and reflect most sublethal effects and an effect at a population level is likely ecologically relevant. But these tests provide bulk measurements and results obtained do not offer information regarding mode of toxic action, as well as requiring between 3 and 7 days to determine growth rates based on an increase in cell number with adequate precision and the test duration can result in substantial losses of toxicant by volatilisation, adsorption to the test container and degradation, all of which might lead to an underestimation of toxicity. Flow cytometry (FCM) is an alternative to the standard population-based endpoints, allowing the rapid and quantitative measurement of functional responses of individual cells to a toxic stress (Cid et al., 1996 and Franqueira et al., 2000). Different studies with microalgae as test organisms have demonstrated that FCM combined with the use of different fluorochromes is a quick and convenient technique to assess toxic effects of contaminants (Adler et al., 2007; Jamers et al., 2009; Prado et al., 2011; Rioboo et al., 2009a,b).

The highest concentration of herbicides measured in flowing surface waters can be associated with pulse discharges (Cedergreen et al., 2005). A study of the potential toxic effects of short-term exposures to high but environmentally relevant concentrations of these pollutants may be of interest. In this work, changes on the physiological status of a microalgal species

(Chlamydomonas moewusil) exposed during $1 \mathrm{~h}$ to a worldwide used herbicide (paraquat) were evaluated by FCM. Besides inherent cell properties (chlorophyll autofluorescence, size and intracellular complexity), cytomic indicators for assessing viability (membrane integrity), metabolic health (esterase activity), oxidative stress (superoxide anion and hydrogen peroxide levels), cytoplasmic and mitochondrial membrane potentials and ionic homeostasis $\left(\mathrm{Ca}^{2+}\right.$ level and cytosolic $\left.\mathrm{pH}\right)$, were also studied.

\section{Materials and methods}

\subsection{Microalgal cultures}

C. moewusii Gerloff (Chlamydomonadaceae) (strain CCAP 11/5B) was maintained in sterile Bristol medium (Brown et al., 1967).

All tests were carried out in an incubator under controlled conditions according to conditions established for maintaining stock cultures: $18 \pm 1^{\circ} \mathrm{C}$, illuminated with a 
photon flux of $70 \mu \mathrm{mol} \mathrm{m} \mathrm{m}^{-2} \mathrm{~s}^{-1}$ under a dark:light cycle of $12: 12 \mathrm{~h}$. Microalgal cells in early exponential growth phase were used as inoculum. Initial cell density was $4 \times$ $10^{5}$ cells $\mathrm{ml}^{-1}$. Paraquat stock solution $(1 \mathrm{mM})$ was prepared by dissolving granulated pure herbicide in sterile distilled water. Cultures without paraquat were included as controls. All cultures were carried out in triplicate. Final paraquat concentrations assayed were 1, 5 and $10 \mu \mathrm{M}$. Actual paraquat concentrations in culture samples were determined by a HPLC-MS protocol (Castro et al., 1999), being close to nominal concentrations: $0.96,4.80$ and $9.60 \mu \mathrm{M}$.

\subsection{Flow cytometric analysis of microalgal cells}

Flow cytometric analysis of $C$. moewusii cells were performed after $1 \mathrm{~h}$ of culture in a Coulter Epics XL4 flow cytometer (Beckman Coulter Inc.) equipped with an argon-ion excitation laser (488 nm), detectors of forward (FS) and side (SS) light scatter and four fluorescence detectors corresponding to different wavelength intervals: $505-550 \mathrm{~nm}$ (FL1), 550-600 nm (FL2), 600-645 nm (FL3) and >645 nm (FL4). Forward scatter and red chlorophyll fluorescence histograms were used to characterise the microalgal population, setting gating levels in order to exclude non-microalgal particles.

Cell suspensions $\left(2 \times 10^{5}\right.$ cells $\left.\mathrm{ml}^{-1}\right)$ were incubated with the appropriate fluorochrome at room temperature and darkness for the necessary time. The lowest fluorochrome concentration and the shortest incubation time were chosen in order to obtain significant and stable staining of cells without toxicity being developed.

For each cytometric parameter investigated, at least $10^{4}$ gated cells were analysed per sample and fluorescence measurements were obtained in a logarithmic scale. Data were collected using listmode files and statistically analysed using the EXPO32 ADC software (Beckman Coulter Inc.). Results were expressed as mean values obtained from histograms in arbitrary units (a.u.), unless it was said otherwise.

\subsubsection{Inherent cell properties}

Aliquots of microalgal cultures were resuspended in phosphate buffered saline solution (PBS, $\mathrm{pH}$ 7.4) and analysed by FCM to study the potential alterations in the forward light scatter (FS), related to the cell size; the side light scatter (SS), related to the intracellular complexity; and the red autofluorescence (FL4), related to the chlorophyll a fluorescence emission, as described in a previous paper ( Prado et al., 2011).

\subsubsection{Cell viability}


Propidium iodide $(\mathrm{Pl})$ can be used to discriminate between viable non-fluorescent cells and non-viable fluorescent cells, then variations on cell viability for $C$. moewusii cultures were studied staining cells with $\mathrm{PI}$ at a final concentration of $4 \mu \mathrm{M}($ Prado et al., 2009a).

\subsubsection{Metabolic activity}

Metabolic health was assessed using a fluorescein diacetate-based cell esterase activity assay, a sensitive and rapid technique to assess phytoplankton metabolic activity (Jochem, 1999 and Prado et al., 2009a).

A kinetic approach to the FDA assay (in fluxo analysis) was used in this work, recording the increase of the FDA-dependent fluorescence after FDA addition (final concentration: $0.2 \mu \mathrm{M}$ ), depending on time ( Prado et al., 2012).

\subsubsection{Oxidative stress}

Oxidative stress in $C$. moewusii was evaluated based on FCM determinations of intracellular levels of superoxide anion radical $\left(\mathrm{O}_{2}{ }^{-}\right)$and hydrogen peroxide $\left(\mathrm{H}_{2} \mathrm{O}_{2}\right)$, using the fluorochromes hydroethidine (HE) (final concentration: 16 $\mu \mathrm{M}$ ) and dihydrorhodamine 123 (DHR123) (final concentration: $29 \mu \mathrm{M}$ ), respectively (Prado et al., 2012).

To avoid the variability of data due to differences in cell size, fluorescence was corrected by cell size estimated using the FS.

\subsubsection{Cytoplasmic membrane potential}

This parameter was monitored using a slow-response potentiometric probe, the bis(1,3-dibutylbarbituric acid) trimethine oxonol $\left(\operatorname{DiBAC}_{4}(3)\right)$, at a final concentration of $1 \mu$ $M($ Prado et al., 2012). Cytoplasmic membrane depolarisation will be reflected in an increased intracellular anionic dye concentration, i.e., by accumulation of dye in the cells, whilst decreased accumulation will reflect hyperpolarisation.

Results were expressed as the percentage of depolarised cells $v s$. the total amount of cells analysed per culture.

\subsubsection{Mitochondrial membrane potential}

The cationic fluorescent dye 5,5',6,6'-tetrachloro-1,1',3,3'-tetraethylbenzimidazolylcarbocyanine iodide $(\mathrm{JC}-1)$ has been reported as a reliable probe for analysing mitochondrial membrane potential by FCM (Salvioli et al., 1997). JC-1 exhibits potential-dependent accumulation in respiring mitochondria that is detectable 
by a fluorescence shift from green to orange, due to the concentration-dependent formation of orange fluorescent oligomers (Reers et al., 1991).

A JC-1 stock solution was prepared in dimethylsulfoxide (DMSO) at a final concentration of $1.5 \mathrm{mM}$. Cell suspensions were incubated with JC-1 (final concentration: $0.8 \mu \mathrm{M}$ ) for $15 \mathrm{~min}$. The fluorescence intensities of both monomer and aggregated JC-1 molecules were recorded by the detectors FL1 and FL2, respectively. Results were expressed as the orange (JC-1 oligomers)/green (JC-1 monomers) fluorescence intensity ratio, a live-time software generated parameter, which is dependent only on the mitochondrial membrane potential (Cassart et al., 2007). This ratio was calculated directly during data acquisition by the cytometer data analysis system, and presented on a linear 1024-channel histogram. The ratio value is given by the mean channel number of this histogram.

To verify the specificity of JC-1 staining, cells were treated with the mitochondrial potential dissipator carbonyl cyanide $m$-chlorophenylhydrazone (CCCP) (final concentration of $49 \mu \mathrm{M}$ during $15 \mathrm{~min}$ ), and stained with JC-1 as described above.

\subsubsection{Intracellular free calcium}

Cytosolic $\mathrm{Ca}^{2+}$ was analysed by FCM staining cells with one of the most sensitive indicators, Calcium Green-1 acetoxymethyl ester (Calcium Green-1 AM) (Lee et al., 1999). The cell-permeant acetoxymethyl ester, non-fluorescent and $\mathrm{Ca}^{2+}$ insensitive, can be passively loaded into cells, where it is cleaved by ubiquitous intracellular esterases to the cell-impermeant fluorescent product Calcium Green-1, which exhibits an increase in fluorescent emission intensity $(530 \mathrm{~nm})$ upon binding $\mathrm{Ca}^{2+}$.

A Calcium Green-1 AM stock solution was prepared in DMSO at a final concentration of $2 \mathrm{mM}$. Cell suspensions were incubated with the fluorochrome (final concentration: $8 \mu \mathrm{M})$ at $30^{\circ} \mathrm{C}$ for $2 \mathrm{~h}$, and the green fluorescent emission was collected by the FL1 detector. In order to avoid the variability due to differences in cell size, fluorescence was corrected by cell size estimated using the FS.

Validation of this staining protocol was carried out by incubating cells with the fluorochrome in the presence of mastoparan, a G-protein activator known to induce $\mathrm{Ca}^{2+}$ release from intracellular stores in C. moewusiicells ( Kuin et al., 2000).

\subsubsection{Intracellular $\mathrm{pH}\left(\mathrm{pH}_{\mathrm{i}}\right)$}

Changes in $\mathrm{pH}_{\mathrm{i}}$ were evaluated using the non-fluorescent acetoxymethyl ester form of the fluorochrome 2',7'-bis(2-carboxyethyl)-5(6)-carboxyfluorescein (BCECF AM). BCECF AM diffuses through the cell membrane and intracellular esterases cleave the ester bond releasing BCECF, which fluoresces according to the $\mathrm{pH} i$. When excited by 
blue light, this fluorochrome emits fluorescence with a maximum at $525 \mathrm{~nm}$ and, in the range of physiological $\mathrm{pH}$, the emission intensity increases with increasing $\mathrm{pH}$. The fluorescence emitted at $620 \mathrm{~nm}$ is not $\mathrm{pH}$-dependent, in spite of this wavelength is not really an isosbestic point (Franck et al., 1996). Therefore, the ratio of the fluorescence emitted at 525 and $620 \mathrm{~nm}$ (green/red) was used to analyse $\mathrm{pH}_{i}$ in cells stained with BCECF, as reported by several authors (Corvini et al., 2000, Cherlet et al., 1999 and Koo et al., 2007). This ratiometric method allowed correcting for differences in fluorochrome uptake and cell size.

A BCECF AM stock solution was prepared in DMSO at a final concentration of $1.2 \mathrm{mM}$. Cell suspensions were incubated with BCECF (final concentration: $6 \mu \mathrm{M}$ ) for $40 \mathrm{~min}$. The green and red fluorescences were collected by the FL1 and FL3 detectors, respectively. The ratio of the two signals was calculated directly during data acquisition by the cytometer data analysis system, and presented on a linear 1024-channel histogram.

Validation of this method was carried out by resuspending BCECF-labelled cells in high $\left[\mathrm{K}^{+}\right]$buffers prepared at increasing $\mathrm{pH}(6,7$ and 8$)$ in the presence of $20 \mu \mathrm{M}$ nigericin and $1 \mu \mathrm{M}$ valinomycin for $10 \mathrm{~min}$ before $\mathrm{FCM}$ analysis, in order to equilibrate the $\mathrm{pH}_{i}$ with that of the surrounding buffer (Corvini et al., 2000).

\subsection{Data analysis}

Data are given as mean values \pm standard error (S.E.) of the mean. To determine significant differences among test concentrations, data were statistically analysed by overall one-way analysis of variance (ANOVA) using SPSS 16.0 software. A $p$ value $<0.05$ was considered statistically significant. When significant differences were observed, means were compared using the multiple-range Duncan test.

\section{Results}

\subsection{Inherent cell properties}

Cell size, intracellular complexity and chlorophyll a fluorescence were affected by a 1 h-exposure of $C$. moewusiit to the assayed paraquat concentrations ( Table 1). The most sensitive parameter was the intracellular complexity, which was significantly increased in all cultures exposed to the herbicide. An increase of cell size was also 
observed in cultures exposed to paraquat although it was statistically significant in cultures exposed to paraquat concentrations of $5 \mu \mathrm{M}$ or highe $\mathrm{r}$ ( Table 1).

Chlorophyll afluorescence was significantly reduced in cultures with a paraquat concentration of $5 \mu \mathrm{M}$ or higher ( Table 1).

Table 1.

Flow cytometric analysis of inherent cell properties (chlorophyll fluorescence, cell size and intracellular complexity) in $C$. moewusiicultures after $1 \mathrm{~h}$ of exposure to different paraquat concentrations. Data, expressed as arbitrary units (a.u.), are mean \pm S.E. Statistically significant differences with respect to control at $p<0.05$ are indicated by ( $\square$ ).

\begin{tabular}{|l|l|l|l}
$\begin{array}{l}\text { Paraquat } \\
(\mu \mathbf{M})\end{array}$ & $\begin{array}{l}\text { Chlorophyllafluorescence } \\
\text { (a.u.) }\end{array}$ & $\begin{array}{l}\text { Cell size } \\
\text { (a.u.) }\end{array}$ & $\begin{array}{l}\text { Intracellular } \\
\text { complexity (a.u.) }\end{array}$ \\
\hline $\mathbf{0}$ & $578 \pm 7$ & $488 \pm 2$ & $187 \pm 2$ \\
\hline $\mathbf{1}$ & $575 \pm 2$ & $498 \pm 2$ & $205 \pm 1$ \\
\hline $\mathbf{5}$ & $550 \pm 6$ & $515 \pm 2$ & $285 \pm 3$ \\
\hline $\mathbf{1 0}$ & $500 \pm 1$ & $522 \pm 4$ & $292 \pm 5$ \\
\hline
\end{tabular}

\subsection{Cell viability}

Cell viability of $C$. moewusii was not significantly affected by the assayed paraquat concentrations. A small percentage of non-viable cells, about 5 percent, began to be apparent only in cultures exposed to the highest paraquat concentration (10 $\mu \mathrm{M})$ ( Fig. 1). 

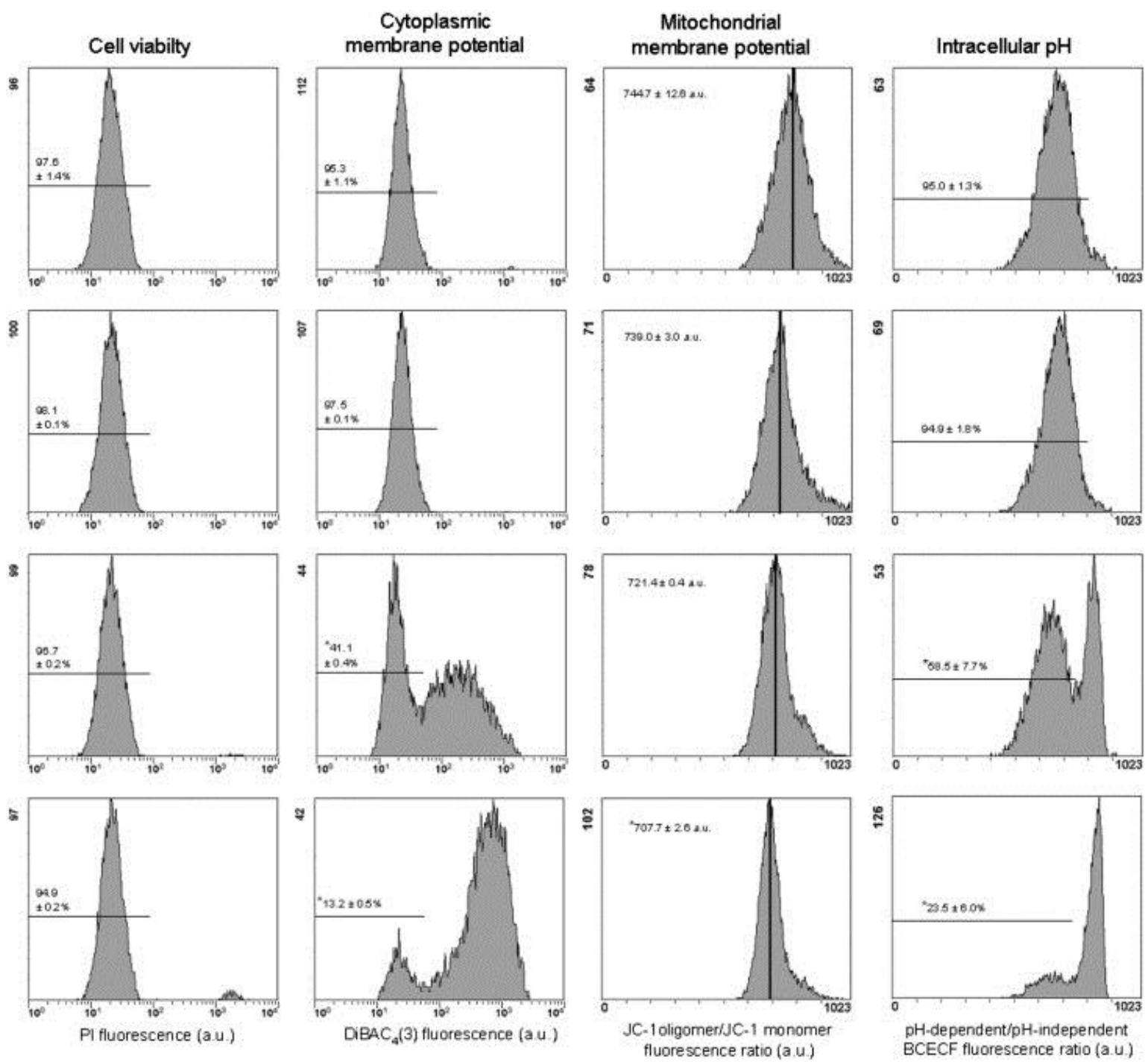

Fig. 1.

Representative histograms of flow cytometric analysis of cell viability, cytoplasmic membrane potential, $\mathrm{pH}$ iand mitochondrial membrane potential in $C$. moewusiicells cultures after $1 \mathrm{~h}$ of exposure to different paraquat concentrations. Histograms show the distribution of fluorescence intensity of the fluorochrome, in logarithmic scale for $\mathrm{PI}$ and $\mathrm{DiBAC}_{4}(3)$ and lineal scale for ratiometric measurements in case of BCECF and JC-1, among the cells analysed ( $Y$-axis: cell number; $X$-axis: fluorescence intensity in arbitrary units, a.u.). Percentages of viable cells, normally polarized cells and non-affected $\mathrm{pH}$ icells are indicated in their respective histograms. Mean mitochondrial membrane potential (a.u.) is indicated for each culture. Data are expressed as mean values \pm S.E. $(\square)$ indicates significant differences with respect to control $(p<0.05)$.

\subsection{Cytoplasmic membrane potential}

Results showed that the $1 \mathrm{~h}$-exposure to paraquat lead to the depolarisation of the plasma membrane in a concentration-dependent percentage of microalgal population (Fig. 1). In cultures exposed to $5 \mu \mathrm{M}$, more than 50 percent of cells were depolarised cells, and only 13 percent of cells in cultures with $10 \mu \mathrm{M}$ maintained a normal cytoplasmic membrane potential comparable to control cells (Fig. 1). 


\subsection{Mitochondrial membrane potential}

Mitochondrial membrane potential of $C$. moewusii cells exposed to paraquat, measured as the orange (JC-1 oligomer)/green (JC-1 monomer) fluorescence ratio, was reduced in a concentration-dependent manner and this reduction was statistically significant in cultures exposed to $10 \mu \mathrm{M}$ ( Fig. 1).

\subsection{Intracellular $\mathrm{pH}$}

C. moewusii $\mathrm{pH}_{\mathrm{i}}$, measured as the green/red BCECF fluorescence intensity ratio, was affected in cultures exposed to paraquat concentrations of $5 \mu \mathrm{M}$ or higher ( Fig.1). In these cultures, a significant percentage of cells showed a $\mathrm{pH} i$ significantly higher with respect to the herbicide non-exposed cultures. In this way, nearly 80 percent of cells exposed to $10 \mu \mathrm{M}$ of paraquat showed an alkalinisation of their cytoplasm ( Fig. 1).

\subsection{Metabolic activity}

The esterase activity analysis revealed that the metabolic activity level of these cells was reduced by the herbicide, in a concentration-dependent manner (Fig. 2). It was already significantly reduced in cultures exposed to $5 \mu \mathrm{M}$, where cells showed an activity twice lower than control cells (Fig. 2). 

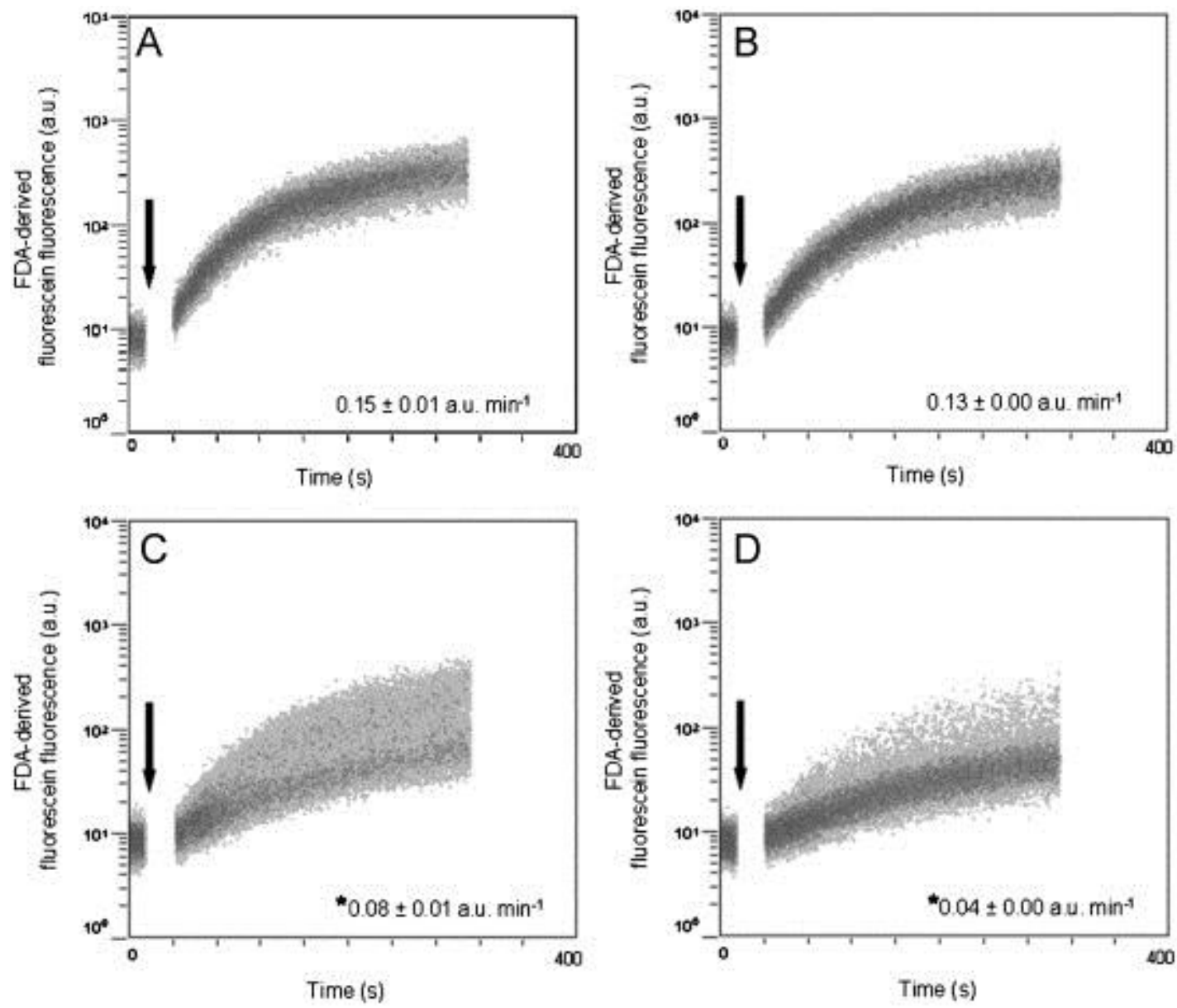

Fig. 2.

Analysis of esterase activity (as an index of metabolic activity) through kinetic plots showing the increase of the FDA-derived fluorescein fluorescence in function of time, for $C$. moewusiicells from control cultures (A) and cultures exposed to $1(B), 5(C)$ and 10 (D) $\mu \mathrm{M}$ of paraquat over $1 \mathrm{~h}$. The arrow indicates the time of addition of FDA to unstained microalgal suspensions. Fluorescence generation rates are indicated in arbitrary units per minute (a.u. $\left.\min ^{-1}\right)$. Data are expressed as mean values \pm S.E. ( $\square$ ) indicates significant differences with respect to control $(p<0.05)$.

\subsection{Oxidative stress}

A $1 \mathrm{~h}$-exposure to paraquat concentrations of $5 \mu \mathrm{M}$, or higher, affected ROS intracellular levels. It was observed a heterogeneous cell response within the population (Fig. 3). 

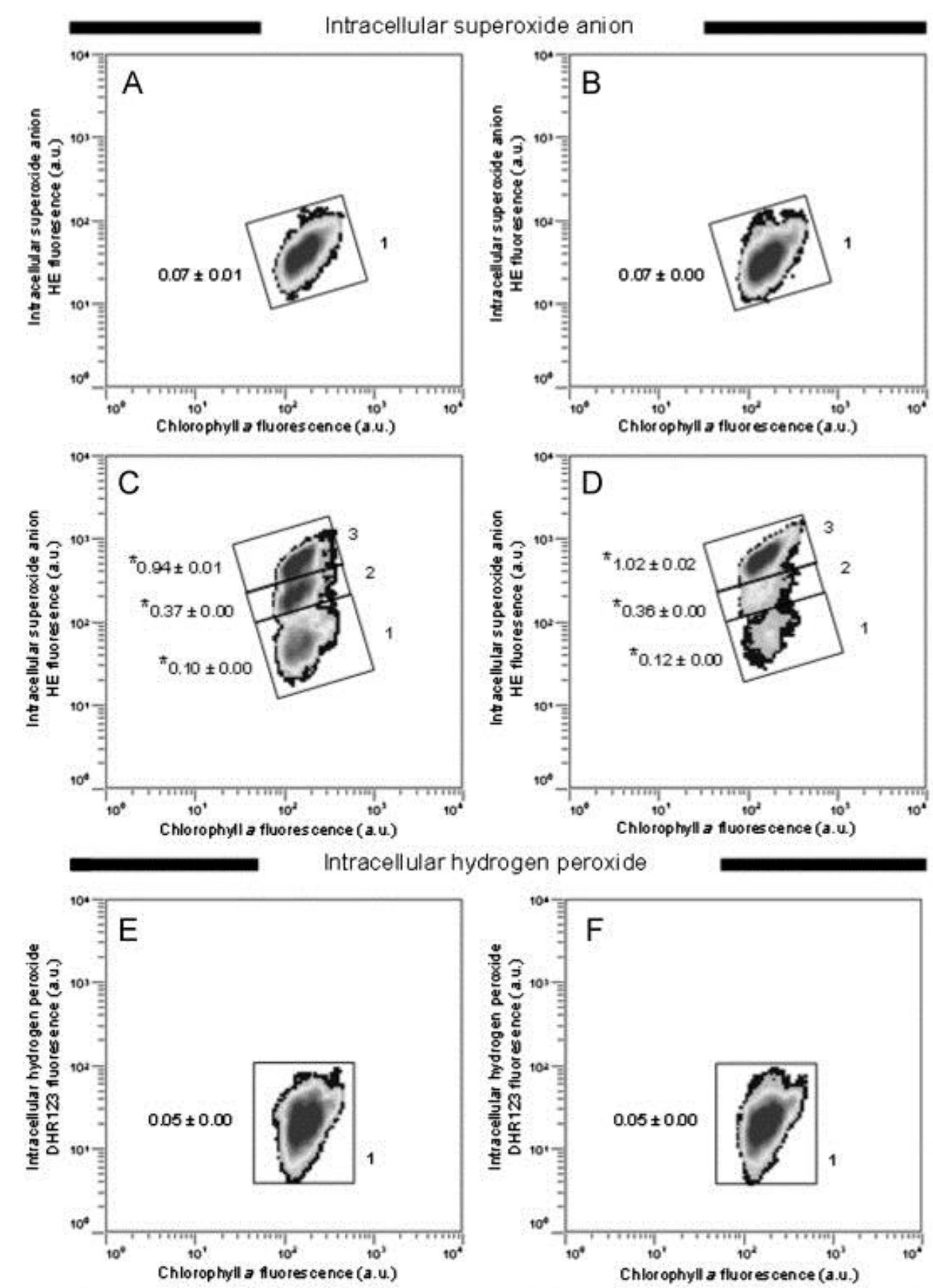

ydrogen peroxide
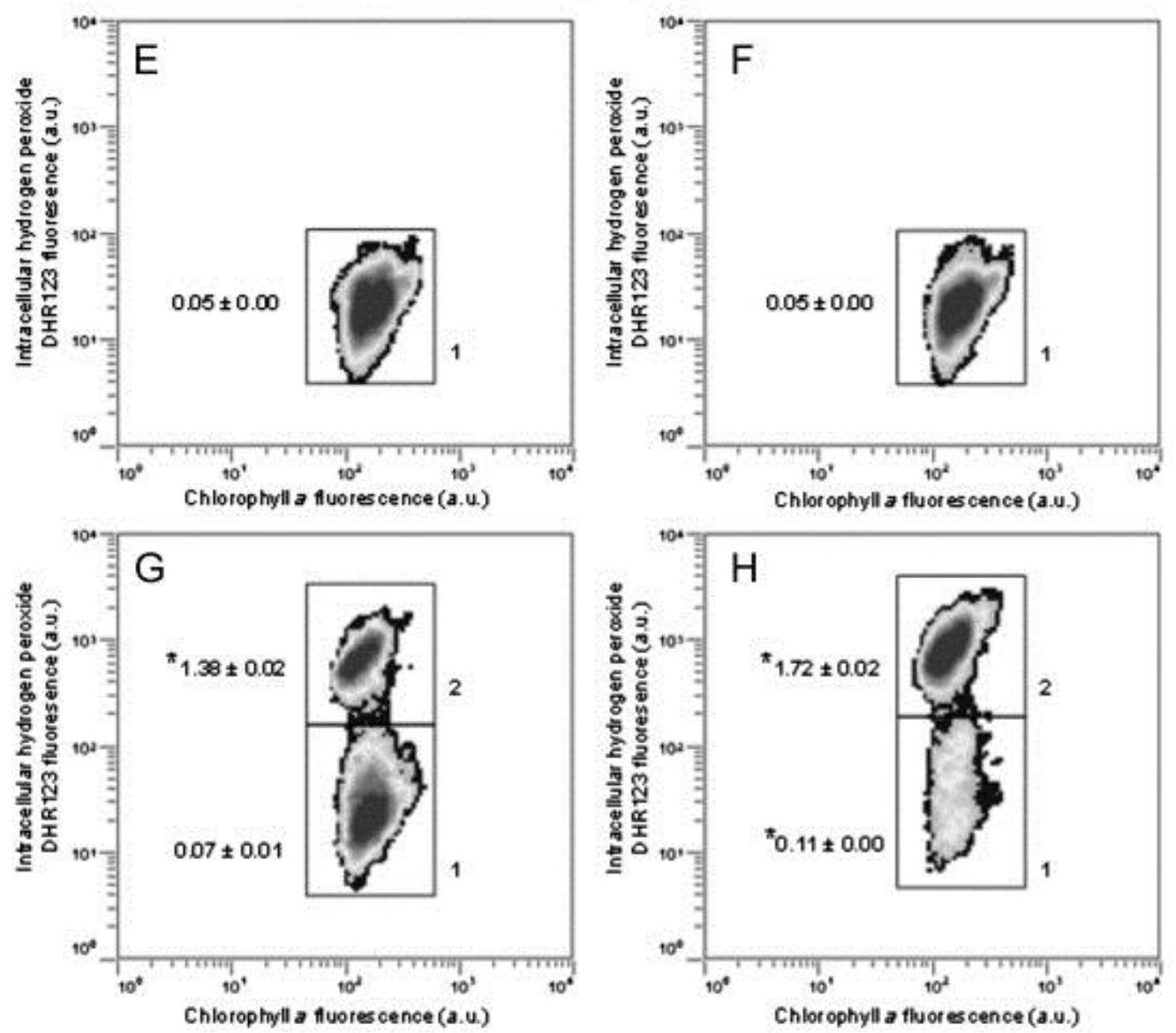
Fig. 3.

Biparametric histograms showing the intracellular levels of superoxide anion $(A, B, C, D)$ and hydrogen peroxide $(E, F, G, H)$, determined by flow cytometry using the fluorochromes $H E$ and DHR123 respectively, vs. chlorophyll fluorescence, for control C. moewusiicultures (A, E) and cultures exposed to $1(B, F), 5(C, G)$ and $10(D, H) \mu M$ of paraquat over $1 \mathrm{~h}$. The regions correspond to each subpopulation differentiated. ROS intracellular level corrected by cell size is indicated for each subpopulation (mean \pm S.E.) and $(\square)$ indicates significant differences with respect to control $(p<0.05)$.

In cultures exposed to 5 and $10 \mu \mathrm{M}$ of paraquat, three cell subpopulations showing different intracellular $\mathrm{O}_{2}$-levels could be distinguished, in any case a level significantly higher than that of control cells (Fig. 3A, C, D). In both cases, the highest percentage of cells (39 percent and 82 percent, respectively) match with the subpopulation showing the highest intracellular O. $2^{-}$level, which was more than ten times the level observed in control cells (Fig. 3A, C, D).

The intracellular $\mathrm{H}_{2} \mathrm{O}_{2}$ level was also increased in cultures exposed to 5 and $10 \mu \mathrm{M}$ of paraquat (Fig. 3E, G, H), although the response was less sensitive. In cultures exposed to $5 \mu \mathrm{M}$ only 37 percent of cells showed a $\mathrm{H}_{2} \mathrm{O}_{2}$ level significantly higher with respect to control. In cultures exposed to $10 \mu \mathrm{M}$, the two cell subpopulations differentiated showed an intracellular $\mathrm{H}_{2} \mathrm{O}_{2}$ level significantly higher with respect to control and, similarly to O. $2^{-}$level, 72 percent of cells belonged to the subpopulation showing the highest intracellular ROS level, which was more than thirty times the level observed in control cells (Fig. 3E, H).

\subsection{Intracellular free $\mathrm{Ca}^{2+}$}

Two cell types could be differentiated in $C$. moewusii cultures: cells with a basal level of cytosolic $\mathrm{Ca}^{2+}\left(\right.$ named 1 in Fig. 4), and cells with an increased $\mathrm{Ca}^{2+}$ level (named 2 in Fig. 4). In cultures exposed to herbicide concentrations of $5 \mu \mathrm{M}$ or higher the percentage of cells with an increased cytosolic $\mathrm{Ca}^{2+}$ level was significantly increased with respect to control cultures, and this effect occurred in a concentration-dependent manner, so that after $1 \mathrm{~h}$ of exposure to $10 \mu \mathrm{M}$ of paraquat 38 percent of cells showed this high intracellular free $\mathrm{Ca}^{2+}$ level, which was more than ten times the basal level observed in most cells of control cultures (Fig. 4). 

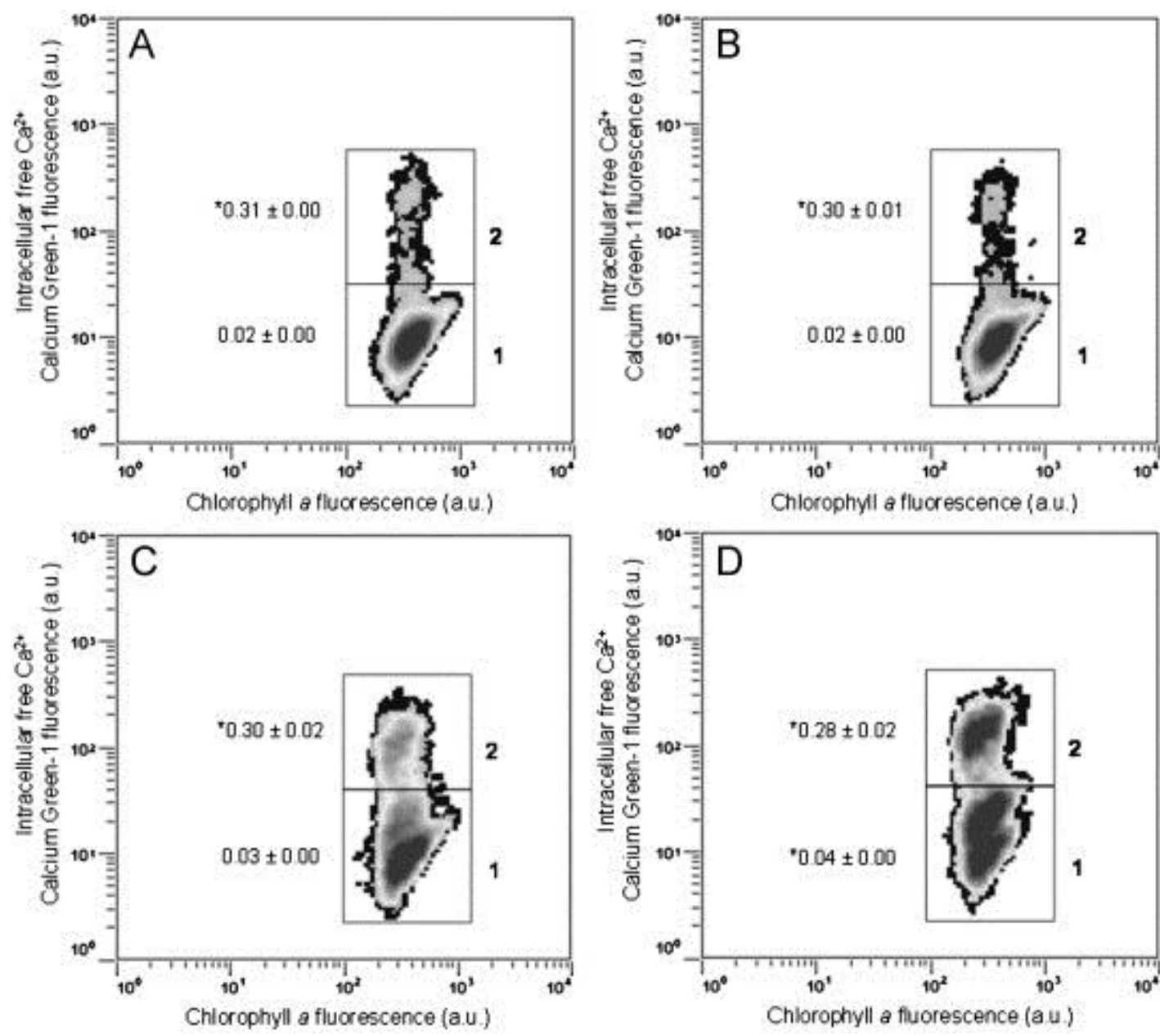

Fig. 4.

Biparametric histograms showing the intracellular free $\mathrm{Ca}^{2+}$ level, determined by flow cytometry using the fluorochrome Calcium Green-1 AM, vs. chlorophyll fluorescence, for control $C$. moewusii cultures (A) and cultures exposed to 1 (B), 5 (C) and 10 (D) $\mu \mathrm{M}$ of paraquat over $1 \mathrm{~h}$. The regions correspond to each subpopulation differentiated. $\mathrm{Ca}^{2+}$ intracellular level corrected by cell size is indicated for each subpopulation (mean \pm S.E.) and $(\square)$ indicates significant differences with respect to the basal level showed by most cells in control cultures $(p<0.05)$.

\section{Discussion}

Paraquat concentrations assayed here, being higher than those used in studies based on a more prolonged exposure to the herbicide (up to $96 \mathrm{~h}$ of exposure to concentrations up to $0.2 \mu \mathrm{M}$ ) (Prado et al., 2009a, Prado et al., 2009b and Prado et al., 2011), are still environmentally relevant, since they are within the range of concentrations applied for aquatic weed control (0.4-19 $\mu \mathrm{M})$ (Bacchetta et al., 2002, Cochón et al., 2007 and Eisler, 1990) and within the range of concentrations found in some watershed areas (up to $11 \mu \mathrm{M}$ ) (Interface, 2008). 
Biomarkers can be of great value in ecotoxicological studies, since they usually represent the first warning signals to predict changes at higher levels of organisation during environmental stress. In this study, the integration of cell physiology analysis by FCM, as technique, and a freshwater microalga, as cell system model, has allowed screening several cell biomarkers of acute toxicity, as a sensitive ecotoxicological tool to early detect toxic effects arising from pulse discharges of contaminants to the environment.

Inherent cell properties analysed were affected, being intracellular complexity the most sensitive parameter (Table 1). The use of chlorophyll fluorescence as an endpoint in common monoalgal toxicity assays has been described in several studies (Eisentraeger et al., 2003 and Geis et al., 2000). Fluorescence yield may be associated with the cellular pigment amount, and also with the current status of the cell and environmental conditions, e.g., under a toxic stress ( Gregor et al., 2008). The autofluorescence decrease can be related to oxidative damage to PSII since the main source for the in vivo emission of chlorophyll a fluorescence is PSII ( Sobrino et al., 2005). On the other hand, ROS produced as a consequence of paraquat action ( Fig. 3) are highly reactive and can cause chlorophyll bleaching ( Ekmekci and Terzioglu, 2005). In fact, long-term exposures of this microalgal species to paraquat caused chlorosis in a concentration-dependent manner (Prado et al., 2011). The overproduction of ROS detected ( Fig. 3) could also explain the increase of intracellular complexity in cultures exposed to paraquat, related to a degradation and disorganisation of cell organelles as a result of the interact of these highly toxic agents with unsaturated lipids of membranes ( Bray et al., 1993 and Suntres, 2002).

Oxidative stress induced by paraquat in $C$. moewusii cells became patently clear by the increased intracellular levels of $\mathrm{O}_{2}{ }_{2}^{-}$and $\mathrm{H}_{2} \mathrm{O}_{2}$ observed in cultures exposed to the herbicide, being O. ${ }^{-}$level more sensitive ( Fig. 3). Paraquat has been reported to be a potent redox-cycling chemical agent ( Bus and Gibson, 1984 and Cochón et al., 2007). Excess $\mathrm{O}_{2}{ }^{-}$results in the production of hydroxyl radicals and $\mathrm{H}_{2} \mathrm{O}_{2}$ by a variety of reactions (Winterbroun, 1981). In cultures exposed to the lowest paraquat concentration, ROS intracellular levels did not show differences with respect to control ( Fig. 3), which may be related with the efficiency of cellular antioxidant mechanisms.

Enzyme inhibition measurements in microalgae are becoming increasingly popular indicators of environmental stress because they offer a rapid and sensitive endpoint (Blaise and Ménard, 1998 and Peterson and Stauber, 1996). In particular, esterase activity, has been proved a useful indicator of environmental stress (Hadjoudja et al., 2009, Jamers et al., 2009 and Yu et al., 2007), and usually a decline in enzyme activity 
is considered indicative of the presence of stress (Franklin et al., 2001 and Regel et al., 2002). This is in accordance with our results, where a reduction of esterase activity is observed in a concentration-dependent manner (Fig. 2). FDA-derived fluorescein is a $\mathrm{pH}$-sensitive probe and its fluorescence intensity is enhanced as $\mathrm{pH}$ increases (Lage et al., 2001, Slavík, 1982 and Visser et al., 1979), but FDA-derived fluorescein fluorescence generation was significantly reduced in cultures exposed to paraquat concentrations of $5 \mu \mathrm{M}$ or higher despite the increase of $\mathrm{pH}_{i}$ (Fig. 1), confirming the negative effect of paraquat on esterase activity.

Perturbations of the cytoplasmic membrane potential have been reported to be sensitive and rapid indicators of physicochemical changes in the extracellular environment (Lloyd et al., 2004). The results obtained revealed that paraquat induces a depolarisation of the cytoplasmic

membrane in $C$. moewusiicells after $1 \mathrm{~h}$ of exposure at concentrations of $5 \mu \mathrm{M}$ or higher ( Fig. 1), but membrane integrity was not affected, so that it can be stated that this treatment damages microalgal plasma membrane mainly by permeabilisation rather than by disruption of membrane integrity. The use of membrane potential probes for viability measurements, in particular $\mathrm{DiBAC}_{4}(3)$, has been reported ( Jepras et al., 1995 and Papadimitriou et al., 2006), although results obtained in the present work can not conclude that depolarised cells were non-viable cells, but the decrease of cytoplasmic membrane potential match with the reduction of metabolic activity. Alterations of the membrane permeability properties can be related to the increase of cell size observed ( Table 1), due to failures in the regulatory cell volume control process.

The increase in the cytosolic $\mathrm{Ca}^{2+}$ level has been usually observed in plant cells in response to different stress factors (Gong et al., 1998, Knight et al., 1997 and Sivaguru et al., 2005). The depolarisation of the cytoplasmic membrane of $C$. moewusiicells exposed to paraquat match with an increase in the intracellular free $\mathrm{Ca}^{2+}$ level and an alkalinisation of the cytosol ( Fig. 1 and Fig. 4), suggesting a possible interaction between these parameters. Short-term exposures to paraquat induce substantial perturbations in the overall cellular ionic homeostasis of $C$. moewusii. Cytoplasmic membrane depolarisation and increases of cytosolic free $\mathrm{Ca}^{2+}$ has been related in several studies ( Akiyoshi et al., 2007, Okazaki et al., 2002 and Sivaguru et al., 2005). A role of $\mathrm{Ca}^{2+}$ as a secondary messenger in the cell response to oxidative stress has been suggested ( Price et al., 1994).

The alkalinisation of cytoplasm in $C$. moewusiicells exposed to high paraquat concentrations could be a consequence of the consumption of intracellular protons by 
reactions implicated in ROS metabolism. A cytosolic alkalinisation has already been related to oxidative stress in microalgae ( Cid et al., 1996).

Obtained results show that mitochondrial membrane potential is the less sensitive parameter among those analysed (Fig. 1). This could be indicative of mitochondria is not the main site of action of paraquat in C. moewusiicells, or this organelle has antioxidant mechanisms that neutralises paraquat radical toxicity, according to Vicente et al. (2001).

\section{Conclusion}

Sublethal paraquat concentrations early affects the physiological status of $C$. moewusii since all the cytotoxicity endpoints assayed showed a significant response after a short period $(1 \mathrm{~h})$ of herbicide exposure. In the present study, most alterations observed could be related with the overproduction of ROS at this early moment.

This microalgal species has shown to be very sensitive to this kind of pollutants and all the parameters assayed can be considered potential and sensitive biomarkers for the acute toxicity of several pollutants (pesticides, metals), except cell viability and the mitochondrial membrane potential. Furthermore, these protocols can be adapted to other sensitive microalgal species (freshwater or marine species) providing a useful technique for ecotoxicity studies.

\section{Acknowledgments}

This work was supported by a research project from Xunta de Galicia (Spain) (08MDS020103PR). R. Prado acknowledges a fellowship from the Diputación Provincial de A Coruña.

\section{References}

N.E. Adler, M. Schmitt-Jansen, R. Altenburger

Flow cytometry as a tool to study phytotoxic modes of action

Environ. Toxicol. Chem., 26 (2007), pp. 297-306 
T. Akiyoshi, N. Tanaka, T. Najkamura, S. Matzno, K. Shinozuka, T. Uchida

Effects of quinine on the intracellular calcium level and membrane potential of PC 12 cultures

J. Pharm. Pharmacol., 59 (2007), pp. 1521-1526

R. Bacchetta, P. Manteca, G. Vailati

Oocyte degeneration and altered ovipository activity induced by paraquat in the freshwater snail

Physa fontinalis (Gastropoda: Pulmonata)

J. Moll. Stud., 68 (2002), pp. 181-186

C. Blaise, L. Ménard

A micro-algal solid phase test to assess the toxic potential of freshwater sediments

Water Qual. Res. J. Can, 33 (1998), pp. 133-151

D.F. Bray, J.R. Bagu, K. Nakamura

Ultrastructure of Chlamydomonas reinhardtii following exposure to paraquat: comparison of wild type and a paraquat-resistant mutant

Can. J. Bot., 71 (1993), pp. 174-182

T.E. Brown, F.L. Richardson, M.L. Vaughn

Development of red pigmentation in Chlorococcum wimmeri (Chlorophyta: Chlorococcales)

Phycologia, 6 (1967), pp. 167-184

\section{J.S. Bus, J.E. Gibson}

Paraquat: model for oxidant-initiated toxicity

Environ. Health Perspect., 55 (1984), pp. 37-46

D. Cassart, T. Fett, M. Sarlet, E. Baise, F. Coignoul, D. Desmecht

Flow cytometric probing of mitochondrial function in equine peripheral blood mononuclear cells

BMC Vet. Res., 3 (2007), pp. 25-31

R. Castro, E. Moyano, M.T. Galceran

Ion-pair liquid chromatography-atmospheric pressure ionization mass spectrometry for the determination of quaternary ammonium herbicides

J. Chromatogr. A, 830 (1999), pp. 145-154

N. Cedergreen, L. Andersen, C.F. Olesen, H.H. Spliid, J.C. Streibig

Does the effect of herbicide pulse exposure on aquatic plants depend on Kow or mode of action?

Aquat. Toxicol., 71 (2005), pp. 261-271 
A. Cid, C. Herrero, J. Abalde

Functional analysis of phytoplankton by flow cytometry: a study of the effect of copper on a marine diatom

Sci. Mar., 60 (1996), pp. 303-308

A.C. Cochón, A.B. Della Penna, G. Kristoff, M.N. Piol, San Martín de Viale, L.C. Verrengia Guerrero, N.R.

Differential effects of paraquat on oxidative stress parameters and poliamine levels in two freshwater invertebrates

Ecotoxicol. Environ. Saf, 68 (2007), pp. 286-292

P.F.X. Corvini, H. Gautier, E. Rondangs, H. Vivier, J.L. Goergen, P. Germain Intracellular $\mathrm{pH}$ determination of pristinamycin-producing Streptomyces pristinaesperalis by image analysis

Microbiology, 146 (2000), pp. 2671-2678

M. Cherlet, P. Franck, P. Nabet, A. Marc

Development and validation of a methodology for intracellular $\mathrm{pH}$ measurements of hybridoma cells under bioreactor culture conditions

Biotechnol. Prog., 15 (1999), pp. 630-639

M.E. DeLorenzo, P. Scott, P.E. Ross

Toxicity of pesticides to aquatic microorganisms: a review

Environ. Toxicol. Chem., 20 (2001), pp. 84-98

A. Eisentraeger, W. Dott, J. Klein, S. Hahn

Comparative studies on algal toxicity testing using fluorometric microplate and Erlenmeyer flask growth-inhibition assays

Ecotoxicol. Environ. Saf., 54 (2003), pp. 346-354

R. Eisler

Paraquat hazards to fish, wildlife, and invertebrates: a synoptic review. Contaminant Hazard Reviews

U.S. Fish Wild. Serv. Biol. Rep., 85 (1.22) (1990), p. 28

\section{Y. Ekmekci, S. Terzioglu}

Effects of oxidative stress induced by paraquat on wild and cultivated wheats

Pestic. Biochem. Physiol., 83 (2005), pp. 69-81

P. Franck, N. Petitipain, M. Cherlet, M. Dardennes, F. Maachi, B. Schutz, L. Poisson, P. Nabet 
Measurement of intracellular $\mathrm{pH}$ in cultured cells by flow cytometry with BCECF-AM

J. Biotechnol., 46 (1996), pp. 187-195

N.M. Franklin, M.S. Adams, J.L. Stauber, R.P. Lim

Development of an improved rapid enzyme inhibition bioassay with marine and freshwater microalgae using flow cytometry

Arch. Environ. Contam. Toxicol., 40 (2001), pp. 469-480

D. Franqueira, M. Orosa, E. Torres, C. Herrero, A. Cid

Potential use of flow cytometry in toxicity studies with microalgae

Sci. Total Environ., 247 (2000), pp. 119-126

S.W. Geis, K.L. Fleming, E.T. Korthals, G. Searle, L. Reynolds, D.A. Karner

Modifications to the algal growth inhibition test for use as a regulatory assay

Environ. Toxicol. Chem., 19 (2000), pp. 36-41

M. Gong, A. van der Luit, M.R. Knight, A.J. Trewavas

Heat-shock-induced changes in intracellular $\mathrm{Ca} 2+$ level in tobacco seedlings in relation to thermotolerance

Plant Physiol., 116 (1998), pp. 429-437

J. Gregor, D. Jancula, B. Marsálek

Growth assays with mixed cultures of cyanobacteria and algae assessed by in vivo fluorescence: one step closer to real ecosystems?

Chemosphere, 70 (2008), pp. 1873-1878

S. Hadjoudja, C. Vignoles, V. Delucht, J.F. Lenain, A.H. Le Jeune, M. Baudu

Short term copper toxicity on Microcystis aeruginosa and Chlorella vulgaris using flow cytometry Aquat. Toxicol., 94 (2009), pp. 255-264

Interface Development Interventions, 2008. Survey on the level of pesticide contaminants in Panigan-Tamugan and Tamodo-Lipadas watersheds: towards the protection of critical water resource areas in Davao City.

A. Jamers, M. Lenjou, P. Deraedt, D. Van Bockstaele, R. Blust, W. de Coen Flow cytometryc analysis of the cadmium-exposed green alga Chlamydomonas reinhardtii (Chlorophyceae)

Eur. J. Phycol., 44 (2009), pp. 541-550

R.I. Jepras, J. Carter, S.C. Pearson, F.E. Paul, M.J. Wilkinson 
Development of a robust flow cytometric assay for determining numbers of viable bacteria Appl. Environ. Microbiol., 61 (1995), pp. 2696-2701

\section{F.J. Jochem}

Dark survival strategies in marine phytoplankton assessed by cytometric measurement of metabolic activity with fluorescein diacetate

Mar. Biol., 135 (1999), pp. 721-728

T. Källqvist, A. Svenson

Assessment of ammonia toxicity in tests with the microalga, Nephroselmis pyriformis,

Chlorophyta

Water Res., 37 (2003), pp. 477-484

H. Knight, A.J. Trewavas, M.R. Knight

Calcium signalling in Arabidopsis thaliana responding to drought and salinity

Plant J., 12 (1997), pp. 1067-1078

M.K. Koo, C.H. Oh, A.M. Holme, S. Pervaiz

Simultaneus analysis of steady-state intracellular $\mathrm{pH}$ and cell morphology by automated laser scaning cytometry

Cytometry Part A, 71 (2007), pp. 87-93

H. Kuin, H. Koerten, W.E.J.M. Ghijsen, T. Munnik, H. van den Ende, A. Musgrave

Chlamydomonas contains calcium stores that are mobilized when phospholipase $\mathrm{C}$ is activated Planta, 210 (2000), pp. 286-294

O.M. Lage, F. Sansonetty, J.-E. O'Connor, A.M. Parente

Flow cytometric analysis of chronic and acute toxicity of copper (II) on the marine dinoflagellate Amphidinium carterae

Cytometry, 44 (2001), pp. 226-235

S. Lee, J. Lee, M. Lee, S. Chung, J. Chung

Advantages of Calcium Green-1 over other fluorescent dyes in measuring cytosolic calcium in platelets

Anal. Biochem., 273 (1999), pp. 186-191

D. Lloyd, J.C. Harris, G.A. Biagini, M.R. Hughes, S. Maroulis, C. Bernard, R.B. Wadley, M.R. Edwards

The plasma membrane of microaerophilic protists: oxidative and nitrosative stress Microbiology, 150 (2004), pp. 1183-1190 
Y. Okazaki, M. Ishigami, N. Iwasaki

Temporal relationship between cytosolic free $\mathrm{Ca} 2+$ and membrane potential during hypotonic turgor regulation in a brackish charophyte Lamprothamnium succinctum

Plant Cell Physiol., 43 (2002), pp. 1027-1035

K. Papadimitriou, H. Pratsinis, G. Nebe-von-Caron, D. Kletsas, E. Tsakalidou

Rapid assessment of the physiological status of Streptococcus macedonicus by flow cytometry and fluorescent probes

Int. J. Food Microbiol., 111 (2006), pp. 197-205

J.L. Pereira, S.C. Antunes, B.B. Castro, C.R. Marques, A.M.M. Gonçalves, F. Gonçalves, R. Pereira

Toxicity evaluation of three pesticides on non-target aquatic and soil organisms: commercial formulations versus active ingredient

Ecotoxicology, 18 (2009), pp. 455-463

S.M. Peterson, J.L. Stauber

New algal enzyme bioassay for the rapid assessment of aquatic toxicity

Bull. Environ. Contam. Toxicol., 56 (1996), pp. 750-757

R. Prado, R. García, C. Rioboo, C. Herrero, J. Abalde, A. Cid

Comparison of the sensitivity of different toxicity test endpoints in a microalga exposed to the herbicide paraquat

Environ. Int., 35 (2009), pp. 240-247

R. Prado, C. Rioboo, C. Herrero, A. Cid

The herbicide paraquat induces alterations in the elemental and biochemical composition of non-target microalgal species

Chemosphere, 76 (2009), pp. 1440-1444

R. Prado, C. Rioboo, C. Herrero, A. Cid

Characterization of cell response in Chlamydomonas moewusii cultures exposed to the herbicide paraquat: Induction of chlorosis

Aquat. Toxicol., 102 (2011), pp. 10-17

R. Prado, R. Rioboo, C. Herrero, P. Suárez-Bregua, A. Cid

Flow cytometric analysis to evaluate physiological alterations in herbicide-exposed

Chlamydomonas moewusii cells

Ecotoxicology, 21 (2012), pp. 409-420 
A.H. Price, A. Taylor, S.J. Ripley, A. Griffiths, A.J. Trewavas, M.R. Knight

Oxidative signals in tobacco increase cytosolic calcium

Plant Cell, 6 (1994), pp. 1301-1310

M. Real, I. Muñoz, H. Guasch, E. Navarro, S. Sabater

The effect of copper exposure on a simple aquatic food chain

Aquat. Toxicol., 63 (2003), pp. 283-291

M. Reers, T.W. Smith, L.B. Chen

J-aggregate formation of a carbocyanine as a quantitative fluorescent indicator of membrane potential

Biochemistry, 30 (1991), pp. 4480-4486

R.H. Regel, J.M. Ferris, G.G. Ganf, J.D. Broookes

Algal esterase activity as a biomeasure of environmental degradation in a freshwater creek

Aquat. Toxicol., 59 (2002), pp. 209-223

C. Rioboo, J.E. O'Connor, R. Prado, C. Herrero, A. Cid

Cell proliferation alterations in Chlorella cells under stress conditions

Aquat. Toxicol., 94 (2009), pp. 229-237

C. Rioboo, R. Prado, C. Herrero, A. Cid

Population growth study of the rotifer Brachionus sp. fed with triazine-exposed microalgae

Aquat. Toxicol., 83 (2007), pp. 247-253

C. Rioboo, R. Prado, C. Herrero, A. Cid

Effects of pesticides on microalgae determined by flow cytometry

C.M. Kanzantzakis (Ed.), Progress in Pesticides Research, Nova Publishers, New York (2009), pp. $477-491$

C. Sabater, J.M. Carrasco

Effects of pyridaphenthion on growth of five freshwater species of phytoplankton. A laboratory study

Chemosphere, 44 (2001), pp. 1775-1781

Article | PDF (81 K) | View Record in Scopus | Citing articles (31)

Salvioli et al., 1997

S. Salvioli, A. Ardizzoni, C. Franceschi, A. Cossarizza 
JC-1, but not DiOC6(3) or rhodamine 123, is a reliable fluorescent probe to assess mitochondrial membrane potential changes in intact cells: implications for studies on mitochondrial functionality during apoptosis

FEBS Lett., 411 (1997), pp. 77-82

M. Sivaguru, Y. Yamamoto, Z. Rengel, S.J. Ahn, H. Matsumoto

Early events responsible for aluminium toxicity symptoms in suspension-cultured tobacco cells New Phytol., 165 (2005), pp. 99-109

J. Slavík

Intracellular $\mathrm{pH}$ of yeast cells measured with fluorescent probes

FEBS Lett., 140 (1982), pp. 22-26

Sobrino, C., Montero, O., Lubián, L.M., 2005. Effect of UV-A and UV-B on diel patterns of growth and metabolic activity in Nannochloris atomus cultures assessed by flow cytometry. Mar. Ecol. Prog. Ser. 293, 29.35.

\section{Z.E. Suntres}

Role of antioxidants in paraquat toxicity

Toxicology, 180 (2002), pp. 65-77

P. Tai, Q. Zhao, D. Su, P. Li, F. Stagnitti

Biological toxicity of lanthanide elements on algae

Chemosphere, 80 (2010), pp. 1031-1035

J.A.F. Vicente, F. Peixoto, M.L. Lopes, V.M.C. Madeira

Differential sensitivities of plant and animal mitochondria to the herbicide paraquat.

J. Biochem. Mol. Toxicol. (15) (2001), pp. 322-330

J.W.M. Visser, A.A.M. Jongeling, H.J. Tanke

Intracellular $\mathrm{pH}$-determination by fluorescence measurements

J. Histochem. Cytochem., 27 (1979), pp. 32-35

C.C. Winterbroun

Production of hydroxyl radicals from paraquat radicals and $\mathrm{H} 2 \mathrm{O} 2$

FEBS Lett., 129 (1981), pp. 339-342

Y. Yu, F. Kong, M. Wang, L. Qian, X. Shi

Determination of short-term copper toxicity in a multispecies microalgal population using flow cytometry 
Ecotoxicol. Environ. Saf., 66 (2007), pp. 49-56

Corresponding author. Fax: +34 981167065 .

Copyright $@ 2012$ Elsevier Inc. All rights reserved. 